

\title{
Plan to Restore Arabian Oryx in Oman
}

\author{
$H$. Jungius
}

The Arabian oryx may now be extinct in the wild. If so it was exterminated by hunters in four-wheel drive vehicles using automatic weapons. Fortunately the species has bred well in captivity thanks largely to the 1962 FPS Operation Oryx, and now animals bred in the USA are becoming available for return to the wild where practicable. Jordan has already embarked on such a project, and Oman, home of the last oryx herds in Arabia, is now planning to release oryx in the Jiddat al Harasis, a vast stony plateau where the last known wild Arabian oryx were killed. In February 1977, at the request of the Oman Government, Dr Jungius, as Director of WWF's Department of Conservation, made a feasibility study, from the report of which the following article is extracted, followed up by a more detailed investigation in March 1978. One most encouraging aspect of the scheme is that the Harasis people regard the oryx as their tribal property. They want the oryx to return, and are prepared to guard them.

\section{Species Distribution, Habitat and Biology}

The Arabian oryx Oryx leucoryx once occurred throughout the Arabian peninsula and much of the Near East. Its northern distribution limits are not known exactly, though it certainly occurred in Iraq and perhaps in the Syrian and Mesopotamian deserts; ${ }^{7}$ but it is feared that since 1972 it has been extinct in the wild. This rapid and dramatic decline has been documented by Talbot ${ }^{13}$ and Dolan, ${ }^{4}$ and they and others ${ }^{811} 12$ have convincingly demonstrated that the cause was neither environmental changes nor traditional tribal hunting from camels using spears or rifles, but human persecution by hunters using fourwheel-drive vehicles and automatic weapons. Animals were chased until they died of exhaustion or stood at bay, thus providing an easy target. Obviously pregnant females and young animals are particularly vulnerable to this kind of hunting, as Newby has shown." This combination of overhunting and selection of females and young animals certainly accelerated the extermination process in spite of this species's unique adaptation to waterless country with sparse vegetation.

In Oman the Arabian oryx (bin sola in Omani) occurred throughout the lowlands south of the north-eastern mountain ranges, but by 1960 they were restricted to the Jiddat al Harasis. ${ }^{2}{ }^{6}$ These were the last wild oryx known in the Arabian peninsula. In the early 1960 s, when numbers were estimated to be still about 100,1011 the Sultan of Muscat forbade oryx hunting from vehicles, and Loyd reports that this ban was respected. Sultan Qaboos, Oman's progressive and far-sighted ruler since 1970, renewed this decree and gave special instructions to the Sheikh of the Harasis tribe to protect the oryx, which again Grimwood and Henderson say was respected by the local Bedouin. Their attitude has not changed, and is certainly of primary importance for any oryx

Opposite: Arabian oryx in Phoenix Zoo, USA, where the original captured animals were taken in 1962 

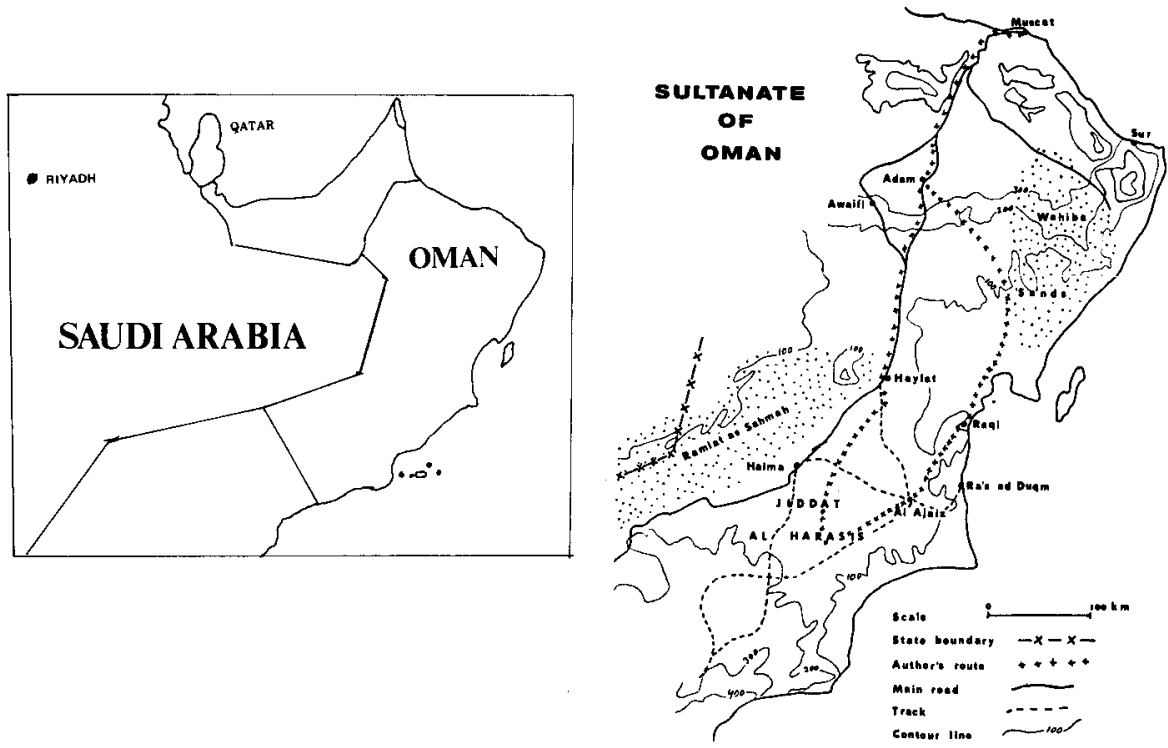

reintroduction programme. Nevertheless, well-equipped and organised foreign hunting parties continued to enter from the north-east, and in October 1972 what may have been the last animals were killed or captured, 35 to $45 \mathrm{kms}$ south-west of $\mathrm{Al} \mathrm{Ajaiz.} \mathrm{Three} \mathrm{were} \mathrm{killed,} \mathrm{and} \mathrm{three} \mathrm{or} \mathrm{four} \mathrm{captured.}{ }^{86}$

The oryx habitat consisted of flat and undulating gravel plains intersected by shallow wadis and depressions and the dunes edging the sand deserts, with a diverse vegetation of trees, shrubs, herbs and grasses. 17157 Oryx seem never to have occurred in mountainous country, ${ }^{1}$ and pure sand deserts, such as the Rub al Khali or the Wahiba Sands, were not permanently inhabited. They are gregarious, living in herds of six to 100 animals, the normal group size being about ten or fewer. ${ }^{1210}$ All observations show males and females in the ratio 1:1, and that old females lead the herds. No observations exist on the size of herd home ranges, and we do not know if distinct sub-populations occurred.

In captivity Arabian oryx are kept in mixed herds and bachelor groups. The herds consist of an adult male, several adult females and their young up to two or three years old; the adult male is dominant, although an adult female may become dominant over other females. In mixed herds and bachelor groups hierarchy is established by fighting, and once an order has been established there is little aggression. But the arrival or removal of animals disrupts the social system and leads to renewed fighting for dominance, characterised by running and chasing. ${ }^{15} 16$ If there is sufficient space, fighting is not severe and the chases are not more than 50 or 100 metres, but this behaviour has to be taken into account both in establishing captive breeding herds and when releasing animals into the wild.

Little is known about movements and migrations, which in ungulates in similar habitats are influenced mainly by rainfall, plant growth and human disturbance. Oryx living on the edge of the sands retire into the dunes whenever disturbed by man, according to Thesiger, Stewart and Grimwood, but these authors were concerned mainly with hunting activities and they say little or nothing about the influence of nomads and their livestock on oryx movements and distribution, though the disturbance and competition for 


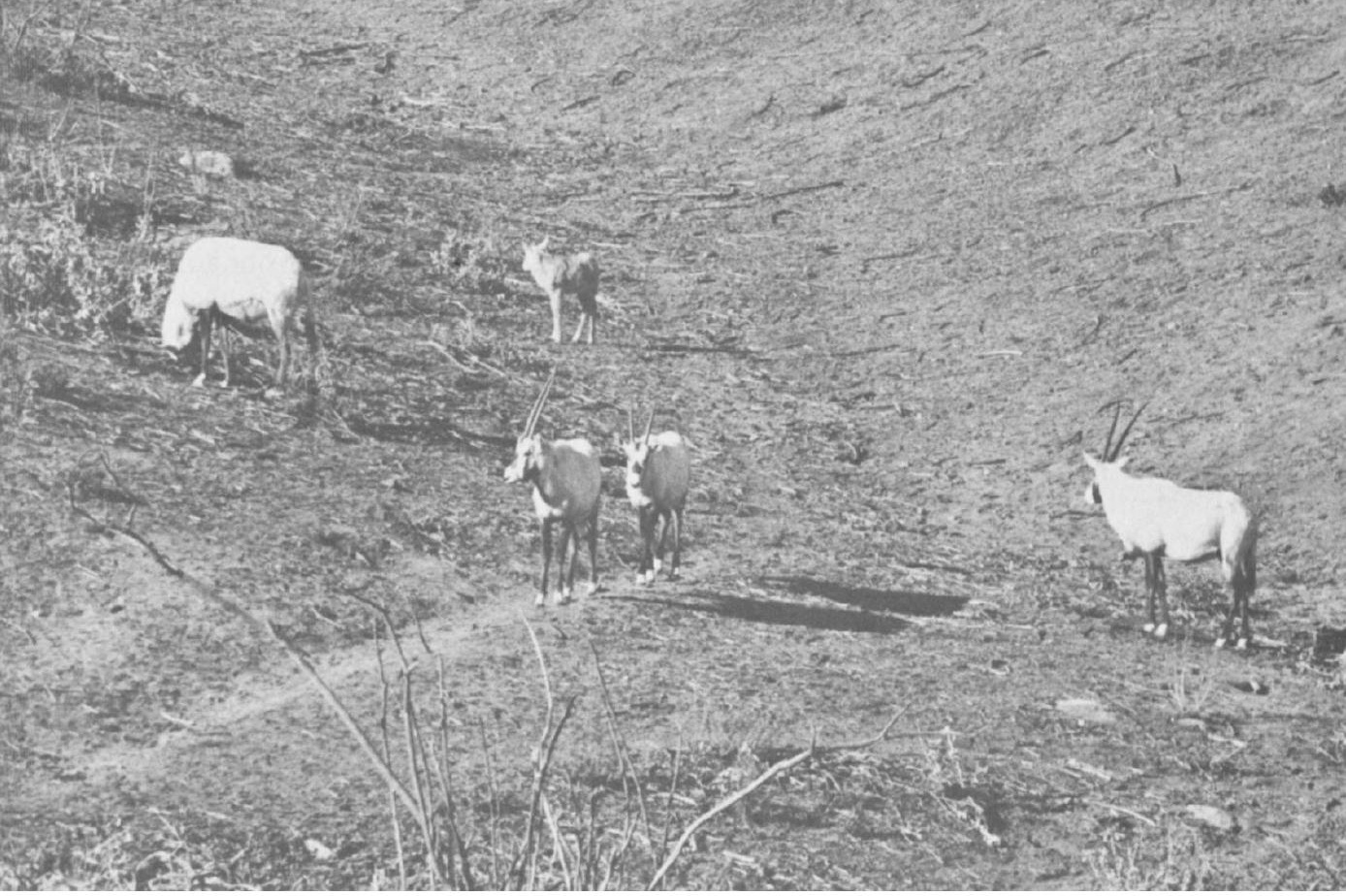

A GROUP at San Diego Zoo, part of the World Herd

grazing caused by the arrival of large herds of goats and camels with herdsmen probably forced the oryx to retreat into less favourable pastures. Thesiger and Stewart assume that oryx stayed in the sands in winter when rain had induced fresh plant growth, and also that summer heat and lack of shade forced them out of the dunes into the cooler open gravel plains where trees and shrubs gave some shade. However, these conclusions have to be considered with care, as they are not based on their own or other scientists' observations, but on information from travellers and tribesmen. A report that oryx in the wild dig shallow depressions with their hooves in soft ground under trees and shrubs for resting has been confirmed in captivity.

Like addax, scimitar-horned oryx and other desert animals, Arabian oryx are apparently able to detect rainfall over great distances, and this stimulates a spontaneous migration to areas of fresh plant growth. As the rainfall is very irregular throughout their habitat, oryx movements must have been spontaneous over hundreds of square kilometres with no fixed patterns, unlike the movements of scimitar-horned oryx in northern Africa, which follow the seasonal rains. ${ }^{11}$

Arabian oryx feed mainly in the early morning, the afternoon and perhaps at night - similar observations have been made in captivity ${ }^{16}$-and often have to cover large distances to find food. Stewart tracked one animal over 90 kilometres in less than 18 hours. They follow wadis and drainage lines and visit small pans and depressions where vegetation is comparatively abundant, and the edges of dunes where there is also vegetation. ${ }^{12}$ Little is known about what they eat. After comparing the literature with his own observations in what was then eastern Aden Protectorate, Stewart concluded that grasses are the main ingredient, but at times they also eat the foliage of some herbs, and the roots, fruits and spadices of others. He noticed that a high proportion of Aristida 
plumosa grass was eaten and a small amount of Lasiurus hirsutus, another grass. Loyd ${ }^{10}$ recorded Asthenatherum forsskalii as another preferred grass, and a sedge, Cyperus conglomeratus, was found in the stomach content of one animal. Faecal analysis revealed five herbaceous species: Tephrosia apollinea (abundant), Tribulus pterocarpus, T. alatus, Cassia senna and Monsonia glauca. According to Stewart local people reported that oryx feed on species of the Cucurbitaceae family, and captive animals ate fruits of Citrullus colocynthis, a wild water melon that stays green into the early hot season. This may well be the main and vital source of water at this period, for Arabian oryx go for many months, even a year, without drinking, getting water from the vegetation, especially fresh green growth, and dew; open water only occurs during the occasional winter rainfall. Many desert grasses and herbs are hygroscopic, and at night, when the ambient humidity is high, can provide much of the water requirements of desert mammals. In captivity oryx with free access to water drink three to nine quarts a day. ${ }^{16}$

Little is known about breeding in the wild. The calving season varies ${ }^{15}$ (as it does in captivity) and the females stay with the herd or family group to calve. ${ }^{10} 12$ The calves may use shallow depressions under shrubs and trees for concealment, often far away. Captive females give birth to their first calf at between $2 \frac{1}{2}$ and $31 / 2$ years old, which means that they can be covered during the first oestrus. ${ }^{4}$ The gestation period is about nine months, and in favourable conditions females may give birth every year, and in any month. ${ }^{16}$ Calves are active shortly after birth, stand up and try to follow their mothers. They seem to be weaned gradually from three weeks of age, and first feeding attempts have been observed at 23 to 25 days. ${ }^{16}$ They are completely weaned by $4-41 / 2$ months (Dolan, pers. comm. 1977).

Predators and diseases appear to have had little effect on oryx populations. Leopards Panthera pardus are extremely rare and hardly enter oryx habitat. Cheetahs Acinonyx jubatus are believed to be almost extinct in Arabia, although a few may survive in southern Oman, but there are no records of cheetah predation on Arabian oryx. Hyaenas Hyaena hyaena and wolf Canis lupus are still widely distributed and may be capable of killing young or sick oryx occasionally, but they are mainly found in mountainous areas and around oases. The most significant natural factor in controlling numbers may have been severe droughts leading to food shortages and severe losses, especially among immature, old and sick animals.

\section{The Reintroduction Area}

The average altitude of the central plateau varies between 100 and 200 metres, rising in the north to 300 metres and in the south to about 400 . Most of it is flat or gently undulating, consisting of gravel and stones mixed with sand, but sand dominates in the depressions. Drainage lines and shallow wadis, from a few to several hundred metres across, are numerous, and pans and depressions up to several hundred metres in diameter are scattered throughout the area. The wadi floors are covered with fine sand, and debris washed down by rain forms a hard layer that is later broken up by erosion and blown away by wind. The whole Jidda is virtually waterless except for a few hand-dug wells which sometimes run dry. Natural permanent wells are found only beneath the limestone escarpment. ${ }^{10} 2$ Bore holes sunk at Al Ajaiz and Haima several years ago are still used to produce water, but the supply is dwindling and may soon stop, particularly at Al Ajaiz. 


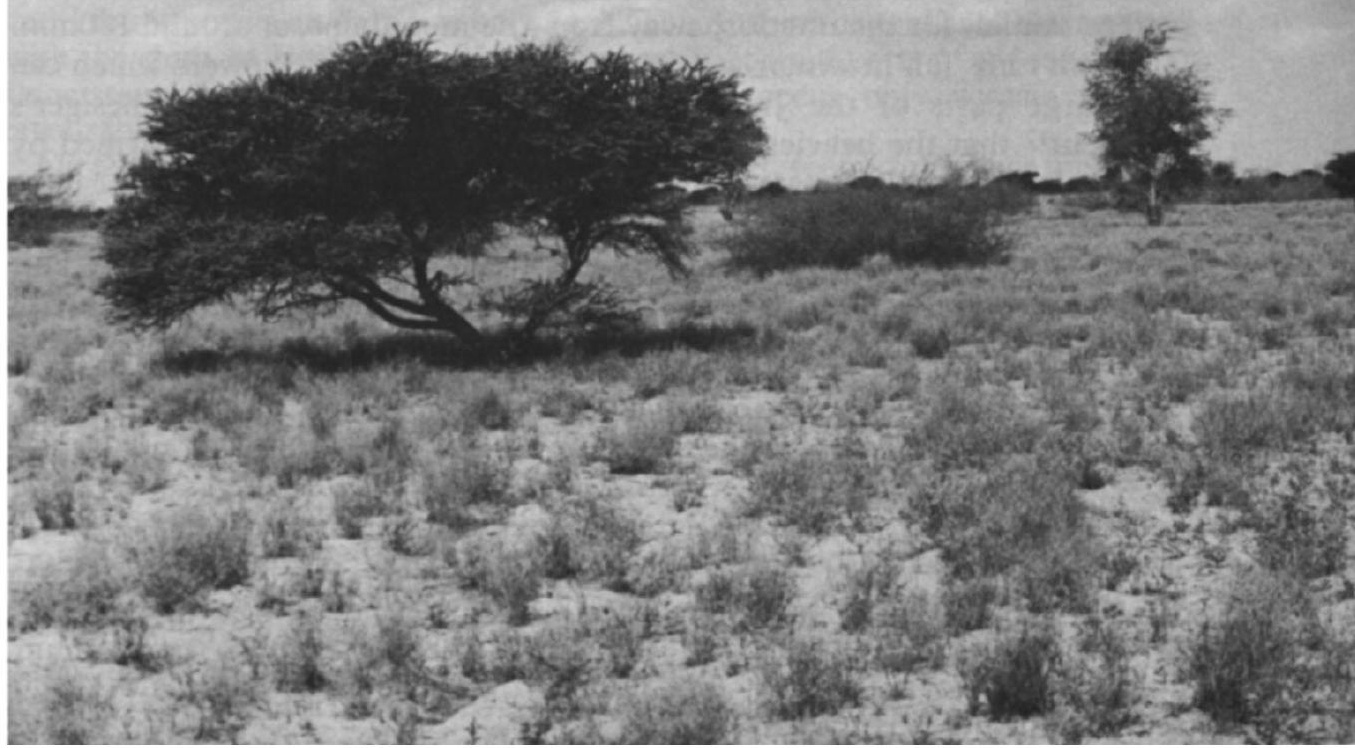

Above: Wadi Yalooni with Acacia tortilis, A. echrenbergiana and Prosopis ceneroria Below: Dry gravel plains of the Jiddatal Harasis with pans and drainage lines covered by vegetation $H$. Jungius 
No climatological data exist for the area. Horn ${ }^{9}$ estimates the maximum average rainfall for the interior, away from the mountains, at around $100 \mathrm{~mm}$. The main rains fall in winter and spring, in sporadic local showers which can leave large parts of the Jidda without rain for several years. Thesiger's statement ${ }^{17}$ that the heaviest rainstorms occur in summer was confirmed by local Bedouin, who indicated that the south-west monsoon in Dofar causes more precipitation in July and August, because cool moist winds reaching the plateau from the south-west produce remarkably high amounts of dew. This occurs even after the monsoon, in October. ${ }^{2}$ The fact that this sporadic rainfall forces the oryx to cover long distances in search of grazing is one that has to be taken into consideration for the reintroduction programme.

There is a similar lack of temperature records. ${ }^{8}$ The minimum and maximum records for Muscat and Salalah on the coast, and so not typical for the Jidda, give only a general idea:
Muscat: June/July
Salalah: May
$\max : 40.9^{\circ} \mathrm{C}$ February: $\max : 32.3^{\circ} \mathrm{C}$ January:
$\min : 16.3^{\circ} \mathrm{C}$ $\min : 17.9^{\circ} \mathrm{C}$ January and February are the coolest months, when temperatures can be extremely low; June, July and August are the hottest, when maximum temperatures may well reach $50^{\circ} \mathrm{C}$, forcing the oryx to seek places with shade trees and shrubs.

The central Jidda is particularly well vegetated, especially with trees and shrubs which are essential to supply food and shade for the oryx. The surrounding area, where the semi-desert vegetation is either very sparse or absent, but can be used by the oryx especially after rain and in the cool season, is at least twice the size of the central area. Most plant growth is concentrated in shallow depressions (pans and wadis); between them are gravel plains where the vegetation is limited to a few Acacia tortilis trees, some Acacia ehrenbergiana shrubs, scattered low-growing shrubs such as Farsetia ramosissima, and the small but very common grass, Stipagrostis plumosa.

In the wadis and pans there are at least two tree species, Acacia tortilis and Prosopis cineraria, both relatively abundant and protected by an ancient Bedouin law, which is respected, that permits only dead trees to be removed for firewood or other purposes; shrubs such as Acacia ehrenbergiana and Ziziphus leucodermis; plants such as Crotalaria wismamii,, Fagonia sp. and Tephrosia apollinea, plus Arnebia hispidissima, Convolvulus species, Corchorus depressus, Dipterygium glaucum, Farsetia ramosissima, Indigofera intricata, Pulicaria crispa and Zygophyllum species; and grasses such as a Chrysopogon sp, Eleusine compressa, Eremopogon oveolatus, Lasiurus hirsutus, Pennisetum dichotomum, Stipagrostis plumosa and S. sokotrana. All these plants, except the Argegia, Farsetia, Pulicaria and the Bygophyllum species, are food plants of wild ungulates according to my own observations and Stewart. ${ }^{12}$

\section{Gazelles}

Two gazelle species inhabit the Jidda: the idmi, mountain or Arabian gazelle Gazella gazella arabica and the rhim, which Harrison? identifies as goitred gazelle Gazella subgutturosa, and Vesey-Fitzgerald ${ }^{17}$ as Loder's gazelle Gazella leptoceros. The rhim inhabits dunes and sand deserts and the adjacent gravel plains and limestone plateaus, ${ }^{17}$ not the central Jidda, although Harrison has 
recorded it from two locations near Adam. It is now reported to be very rare, ${ }^{2}$ and I found tracks on only two occasions. The Arabian oryx shared this habitat with the rhim, at least during the winter, when it used parts of the sands, but associations between oryx and rhim seem to occur only occasionally at favourable grazing sites. ${ }^{12}$

On the gravel plains the idmi, which is abundant, seems to replace the rhim; in one day we counted $84 \mathrm{idmi}$ in an area of $600 \mathrm{sq} \mathrm{km}$. In some wadis or depressions up to 27 animals were grazing together, even where there had been little or no rain that season. Flight distances under 50 metres were not uncommon. There was a high proportion of young, and their tameness was in marked contrast to those in areas visited earlier. This and the high reproduction rates are good indications that the animals are little disturbed and that local people respect the laws prohibiting hunting. Indeed the abundance of game in the Jiddat al Harasis is remarkable; not only gazelle but hare, sandgrouse and partridge are present in good numbers. Moreover, falconry is not practised by Omanis. Permission is no longer granted for hunting parties from other countries, and illegal entry is now being effectively controlled by the North Oman Border Scouts, regular army patrols, the police post at Haima and the PDO Oil Company installation at Qarn Alam. Wolf and hyaena are the only large predators, and neither is common. I saw one track of a wolf or hyaena at the Raqi well, $70 \mathrm{kms}$ north of Al Ajaiz. There are no records of caracal, leopard or cheetah.

\section{The People}

The Harasis people are a small tribe-350-500 people-of nomad stockbreeders which has lived in the area since time immemorial. They have no villages, moving around continually in search of good pasture for their sheep, goats and camels. Their migrations follow no regular pattern and are determined by the rainfall; they even enter the edge of the Rub al Khali if rain has fallen there. I saw herds of 100 to 150 goats grazing and browsing close to herds of gazelles. Camels were in small groups of four to twelve animals and widely dispersed. Grazing pressure may sometimes be locally heavy but I saw no overgrazing or serious damage to the vegetation or soil.

The traditional Harasis way of life has been only slightly affected by the oil companies. When the companies arrived most men went to work for them, although livestock breeding continued as before, the stock being looked after by women, children and old people. But when no oil was found in the Jidda most of the men returned to their families. National statistics show a decline in camel breeding, due to the reduced need for transport animals with the arrival of trucks and four-wheel drive vehicles, but goat and sheep stocks are increasing slightly, and the same trends seem to apply to the study area.

Until 1965 the Harasis used to hunt oryx occasionally by camel..$^{10}$ Loyd and Butler report that they consider the oryx a tribal property and are anxious to prevent its extermination (pers. comm. 1977). All the people we questioned said that all Harasis would whole-heartedly support a reintroduction programme, and influential people of the area have confirmed this. Moreover, there has been no significant change in the habitat or the land use, and the human population and livestock numbers have remained relatively stable. The only major developments are a main road in the north and a well at Al Ajaiz, and no others are envisaged.

The Jiddat al Harasis thus provides an ideal area to reintroduce Arabian 
oryx. Obviously it is important that either the whole or large parts of it should be proclaimed a game or wildlife reserve, and this is under consideration. A guard force is essential and educational campaigns should be directed to both local people and the neighbouring countries from which hunting parties have come in the past. Another recommendation is that, in order to ensure the greatest possible genetic diversity, stock for the reintroduction programme be obtained from different breeding centres. These include the Phoenix, San Diego, Brownsville and Los Angeles zoos, and other collections.

\section{Acknowledgments}

Grateful acknowledgment is made to the Sultanate of Oman, Ministry of Diwan Affairs, which offered me the opportunity to make this study and which covered all travel expenses to Oman and inside the country. I am obliged to the Director General of the World Wildlife Fund for permission to undertake this study. I am particularly grateful to Mr Ralph Daly, Adviser for the Preservation of the Environment of the Sultanate of Oman, for arranging my visit and for providing valuable information and good advice. I also acknowledge with thanks the help of Dr R. M. Lawton who collected the botanical specimens, and of Miss D. Hillcoat, of the British Museum (Natural History), who did the identification. I also wish to thank Dr J. Dolan, Dr C. Holloway and Dr N Woodford for their support of the programme and advice on its implementation.

\section{References}

1. BADDELEY, M. R. 1962. Pers. comm. to Stewart 1963.

2. BUTLER, 1965. Report on travels to Oman. Unpublished. Pers. comm. to Daly 1977.

3. DALY, R. H. 1977. Pers. comm.

4. DOLAN, J. M. 1973. The return of the unicorn. Zoo Nooz, Zoological Society of San Diego, 46 2: 6-10.

1976. The Arabian oryx: its destruction, captive history and propagation. Int. Zoo Yb. 16: 230-239.

5. GILLET, H. 1971. L'oryx algazelle et l'addax: distibution géographique, chances de survie. C.r. somm. Séanc. Soc. Biogéogr. No. 405: 177.

6. GRIMWOOD, I. R. 1964. Operation Oryx: the second stage. Oryx 7: 223-225.

7. HARRISON, D. L, 1968. The large mammals in Arabia. Oryx 9: 357-363.

8. HENDERSON, D. S. 1974a. The Arabian Oryx: a desert tragedy. National Parks and Conservation Magazine 48 5: 15-21.

1974b. Were they the last Arabian oryx? Oryx 12: 347-350.

9. HORN, P. M. 1976. Rainfall in Oman. Mimeo.

10. LOYD, M. 1965. The Arabian oryx in Muscat and Oman. E. Afr. Wildl. f. 3:129127.

11. NEWBY, J. E. 1974. The ecological resources of the Ouadi Rime-Ouadi Achim Faunal Reserve. UNDP/FAO Wildlife Conservation and Management Project CHD/69/004.

12. STEWART, D. R. M. 1963. The Arabian oryx. E. Afr. Wildl. F. 1: 103-117. 1964. The Arabian oryx-2. E. Afr. Wildl. F. 2: 168-169.

13. TALBOT, L. M. 1960. A look at threatened species. Oryx 5: 157-293.

14. THESIGER, W. 1947. A new journey in southern Arabia. Geogr. 9.8 :

15. THORP, J. L. 1964. The Arabian oryx. Arizona Zoological Society Special Bulletin No. 1: 1-14.

16. TURKOWSKI, F. J., and G. C. MOHNEYA 1969/1971 History, management and behaviour of the Phoenix Zoo Arabian oryx herd. Arizona Zoological Society Special Bulletin No. 2: 1-36.

17. VESEY-FITZGERALD, Wildlife in Arabia. Oryx 1:232 